\title{
A Novel Alu-Mediated Xq28 Microdeletion Ablates TAZ and Partially Deletes DNL1L in a Patient With Barth Syndrome
}

\author{
Harinder R. Singh, ${ }^{1}$ Zhao Yang, ${ }^{2}$ Saad Siddiqui, ${ }^{1}$ Liana S. Peña, ${ }^{2}$ Brandy H. Westerfield, ${ }^{2}$ Yuxin Fan, ${ }^{2}$ \\ Jeffrey A. Towbin, ${ }^{2}$ and Matteo Vatta ${ }^{2 *}$
}

${ }^{1}$ Children's Hospital of Michigan, Division of Cardiology, The Carman and Ann Adams, Department of Pediatrics, Wayne State University School of Medicine, Detroit, Michigan

${ }^{2}$ Department of Pediatrics [Cardiology) and John Welsh Cardiovascular Diagnostic Laboratory, Baylor College of Medicine, Texas Children's Hospital, Houston, Texas

Received 12 January 2009; Accepted 15 February 2009

\section{TO THE EDITOR:}

Barth syndrome is characterized by X-linked cardiomyopathy, neutropenia, skeletal myopathy, growth delays, lipid abnormalities and increased excretion of 3-methylglutaconic acid [Barth et al., 1983; Kelley et al., 1991]. The locus causing Barth Syndrome was mapped to Xq28 and the tafazzin or TAZgene was identified in 1996 [Bione et al., 1996]. Since then, more than 90 mutations in the TAZ gene have been identified according to the Barth Syndrome Foundation (www.barthsyndrome.org), which include frameshift, duplication, nonsense and missense mutations [Johnston et al., 1997; Brady et al., 2006]. There is no strong genotype-phenotype correlation, with patients presenting with a variable course of the disease [Gedeon et al., 1995; Barth et al., 2004]. Cardiac involvement, usually mild to moderate, occurs during the first year of life and presents as dilated cardiomyopathy (DCM), endocardiofibroelastosis (EFE), or isolated left ventricular noncompaction (LVNC) [Spencer et al., 2006]. DCM is more common and is characterized by left and right ventricular dilation, with the left chamber being the more severely involved, while septal and left ventricular (LV) wall thickness can also occur. Cardiac hemodynamics in Barth syndrome subjects usually demonstrates moderately reduced ejection fraction (EF), fractional shortening (FS) and increased left ventricular internal dimension in diastole (LVIDd) [Spencer et al., 2006].

In this study, we analyzed a 7-month-old previously healthy African American male, admitted to the hospital in moderate respiratory distress, congestive heart failure (CHF), and unremarkable family history. Two-dimensional echocardiogram revealed a dilated left ventricle $(\mathrm{LV}), \mathrm{FS}=10 \%$, and $\mathrm{EF}=22 \%$ consistent with DCM without evidence of hyper-trabeculated LV, great arteries or coronary arteries anomalies. He had normal fatty acid, vanilmandelic acid (VMA) and amino acid levels, while 3methylglutaconic acid levels were increased. In addition to the cardiovascular and metabolic defects, the 7-month-old patient also
How to Cite this Article:

Singh HR, Yang Z, Siddiqui S, Peña LS,

Westerfield BH, Fan Y, Towbin JA, Vatta M.

2009. A novel Alu-mediated Xq28

microdeletion ablates $T A Z$ and partially

deletes $D N L 1 L$ in a patient with Barth

syndrome.

Am J Med Genet Part A 149A:1082-1085.

presented with neurological alterations including recurrent seizures and hypotonia.

After a few months from discharge, the patient was readmitted to the hospital due to hypoglycemia and deteriorating CHF despite optimal medical therapy. Due to his worsening hemodynamic conditions he underwent mechanical support through a Berlin Left Ventricular Assistive Device implantation followed by Extra Corporeal Membrane Oxygenation (ECMO). He was listed for heart transplantation. Prior to listing the patient for transplant, an extensive work up was performed. The electromyography and the nerve conduction study suggested skeletal myopathy and the muscle biopsy demonstrated non-specific changes with few scattered moderately atrophic fibers. The complete blood count (CBC) done during this admission (and on subsequent review of previous $\mathrm{CBC}$ reports) identified severe neutropenia showing a cyclical pattern ranging from a neutrophil count of 100 cells $/ \mathrm{mm}^{3}$ to

Harinder R. Singh and Zhao Yang contributed equally to this work. ${ }^{\star}$ Correspondence to:

Matteo Vatta, Pediatrics (Cardiology), Baylor College of Medicine, Texas Children's Hospital, 1102 Bates St., F.C. 430.04, Houston, TX 77030.

E-mail: mvatta@bcm.tmc.edu

Published online 22 April 2009 in Wiley InterScience

(www.interscience.wiley.com)

DOI 10.1002/ajmg.a.32822 
14,700 cells $/ \mathrm{mm}^{3}$, which suggested the diagnosis of Barth syndrome. The patient underwent an orthotropic cardiac transplantation at 2 years of age and pathological analysis on the explanted heart, which weighed $128 \mathrm{~g}$, identified DCM with disorganized myocytes, focal hypertrophic changes, perinuclear myocytolysis and EFE affecting both ventricles with focal epicardial calcifications with foreign body giant cell reaction.

The hemodynamics of this patient demonstrates a FS of $41 \%$ with excellent contractility. The neutropenia continues to be an issue with the absolute neutrophil count ranging between 0 and 3,000 (predominantly $<1,500$ ), his skeletal myopathy has been stable and his tone has improved with physical therapy showing no residual weakness. The patient is growing according to the normal parameters for his age. He is still followed by Hematology/Oncology and continues to have intermittent neutropenia but has not required admissions for these episodes. He is also followed by a neurologist because of previously recurrent seizures that required treatment with Trileptal. However, the patient has not presented with seizure episodes for about a year.

Blood was obtained after informed consent, according to the Baylor College of Medicine Institutional Review Board (IRB), for DNA extraction. Using polymerase chain reaction (PCR) and direct DNA sequencing, open reading frame/splice site mutational analysis was performed on the TAZ gene (NCBI\# NM_000116). PCR products were purified using exonuclease I (USB, Cleveland, $\mathrm{OH}$ ) and shrimp alkaline phosphatase (Roche, Indianapolis, IN). DNA sequence analysis was performed using Big Dye terminator chemistry (v3.1) and an ABI3730 genetic analyzer (Applied Biosystems, Foster City, CA). The comprehensive mutational analysis failed to yield a detectable product for all 11 exons of the TAZ gene. Therefore, a genomic DNA deletion was suspected. In order to map the potential breakpoints on the $T A Z$ gene, sequential PCR was performed using primers upstream and downstream the coding sequence. Long fragment PCR product was obtained using primers flanking the deleted region: $5^{\prime}$-TGGCTGCACACTTCTGAGTT- $3^{\prime}$ and $5^{\prime}$-AGGTGGGGAATTGCTAGGTC- $3^{\prime}$. Amplified PCR product was purified and directly sequenced as described above.

Sequential PCR primers followed by junctional fragment PCR located the breakpoints $1.1 \mathrm{~kb}$ upstream (5'-UTR) and $12.6 \mathrm{~kb}$ downstream $\left(3^{\prime}\right.$-UTR) the start codon (ATG) of the TAZ gene. Computational analysis of the $T A Z$ genomic sequence encompassing the breakpoint identified Alu-repeat elements of distinct subfamilies in both $5^{\prime}$ - and $3^{\prime}$-UTR regions of TAZ. The breakpoint sequence identified a 29-bp core motif (Fig. 1A) with 100\% homology to an AluSx-repeat at the $5^{\prime}$-UTR and one AluSq-repeat element at the $3^{\prime}$-UTR of TAZ (Fig. 1B). Alu-mediated microdeletion due to homologous unequal recombination is a very well described mechanism [Batzer and Deininger, 2002], supported by the high homology between the two Alu-elements involved $(>78 \%)$. In addition, successful amplification of adjacent microsatellite markers (Table I) and the Emerin (EMD) gene, which is

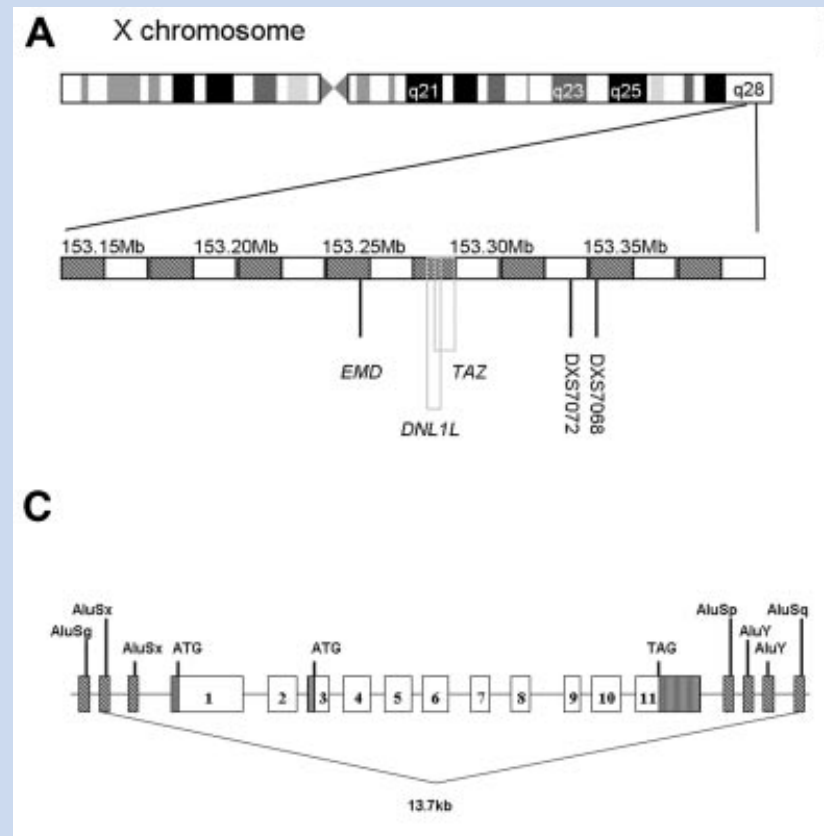

B

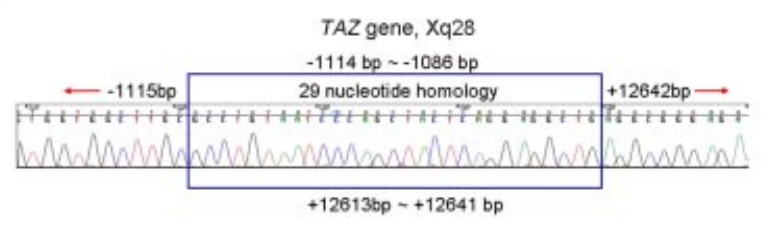

D

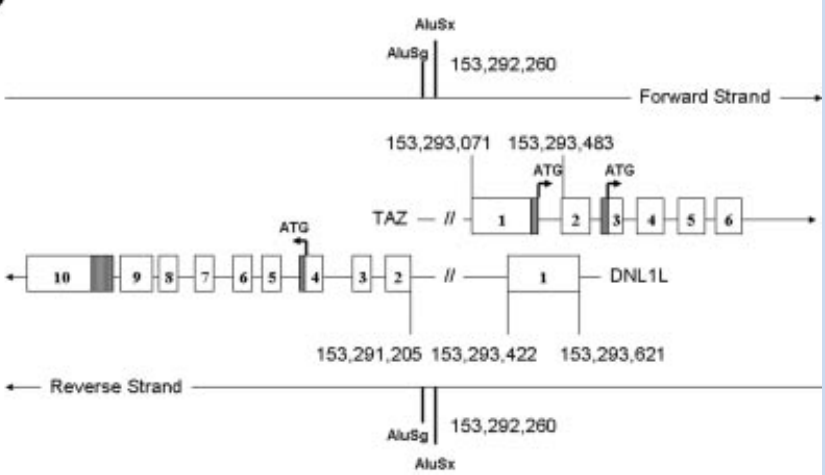

FIG. 1. A: Chromosomal deletion study using microsatellite markers and $\varepsilon$ merin [ $E M D$ ] gene in Xq27-28 to map the deletion. Successfully amplified products are defined by the black solid bar, while markers that failed to amplify are labeled as red squares. B: The sequence at the joining of the deletion ends and TAZ gene location in Xq28. There is a 29-nucleotide homology between the 2 breakpoints. C: Relative location of the full-length Alurepeat elements relative to the $5^{\prime}$ - and $3^{\prime}$-UTR of the TAZ gene. D: Relative chromosomal position, expressed in base pairs, of the $5^{\prime}$ AluSx-repeat involved in the microdeletion and the overlapping TAZ and DNL1L exonic and intronic sequences. [Color figure can be viewed in the online issue, which is available at www.interscience.wiley.com.] 
TABLE I. Panel of Polymorphic Markers and Gene Analysis on Chromosome X

$\begin{array}{llll}\text { Marker name } & \begin{array}{c}\text { Physical } \\ \text { location (bp) } \\ 66963873\end{array} & \begin{array}{c}\text { Cytogenetic } \\ \text { location } \\ \text { Xq12 }\end{array} & \begin{array}{c}\text { Amplified } \\ \text { Yes }\end{array} \\ \text { DXS8040 } & 87160632 & \text { Xq21.31 } & \text { Yes } \\ \text { DXS1050 } & 105909211 & \text { Xq23.3 } & \text { Yes } \\ \text { DXS8097 } & 114561198 & \text { Xq24 } & \text { Yes } \\ \text { DXS8055 } & 115610089 & \text { Xq25 } & \text { Yes } \\ \text { DXS8093 } & 125610 \text {-3 } & \text { Yes } \\ \text { DXS8041 } & 133531399 & \text { Xq26.3 } & \text { Yes } \\ \text { DXS984 } & 139459394 & \text { Xq27.1 } & \text { Yes } \\ \text { DXS1227 } & 140630081 & \text { Xq27.2 } & \text { Yes } \\ \text { DXS998 } & 150167607 & \text { Xq27.3 } & \text { Yes } \\ \text { DXS8061 } & 151772275 & \text { Xq28-tel } & \text { Yes } \\ \text { EMD } & 153260751 & \text { Xq28-tel } & \text { Partially } \\ \text { DNL1L } & 153293621 & \text { Xq28-tel } & \text { No } \\ \text { TAZ } & 153293071 & \text { Xq28-tel } & \text { Yes } \\ \text { DXS7072 } & 153333143 & \text { Xq28-tel } & \text { Yes } \\ \text { DXS7068 } & 153341684 & \text { Xq28-tel } & \text { Yes } \\ \text { DXS7010E } & 153382680 & \text { Xq28-tel } & \end{array}$

located $20 \mathrm{~kb}$ upstream the TAZ gene (Fig. 1B) suggested that the recombination event did not impact other chromosomal regions.

However, careful analysis of neighboring genes revealed that the Alu-mediated chromosomal deletion involved the $5^{\prime}-\mathrm{UTR}$, the first exon and partial intron1 of three out of six isoforms of the Deoxyribonuclease I-like 1 Precursor $(D N L 1 L)$ gene (www.ensembl.org; ENSG00000013563), which is transcribed on the opposite strand $\left(3^{\prime}>5^{\prime}\right)$ and it partially overlaps with TAZ. $D N L 1 L$ is highly expressed in cardiac and skeletal muscle, although very little is known about its function and it has never been involved in Barth syndrome before. DNL1L was shown to localize to the plasma membrane and to early endocytic vesicles to hydrolyze the internalized extracellular DNA, thereby protecting cells from invasion by foreign genes [Shiokawa et al., 2007]. In addition, a deletion polymorphism has been studied for probable association with acid maltase deficiency disorders and Pompe disease [Malferrari et al., 2001], although this association appears controversial [Lichtenbelt et al., 2006]. Unfortunately, we could not obtain consent to acquire myocardial tissue from our patient to investigate the involvement of DNL1L in the clinical presentation of our subject and whether the Alu-mediated deletion led to alterations in DNL1L expression. Therefore, because of the extent of the deletion, we can only speculate that, at least three out of six DNL1L isoforms would not be expressed in our patient's heart consistent with a probable partial functional ablation in addition to the null $T A Z$ mutation. Further studies on DNL1L function are warranted to determine its significance in cardiac biology and its possible involvement in Barth syndrome.

Clinically, our patient demonstrated a very severe cardiomyopathy with rapid progression requiring cardiac transplantation, cyclical neutropenia with very low counts, dramatic hypotonia and weakness. Genetically, we have identified the first chromosomal microdeletion (13.7 kb on Xq28) due to an Alu-mediated unequal homologous recombination involving the entire $T A Z$ gene and partially the DNL1L gene overlapping on the opposite strand. The microdeletion included part of the $5^{\prime}$-UTR, the entire coding sequence and a fragment of the $3^{\prime}$-UTR of $T A Z$, all the sequence upstream the first exon and part of the intron 1 of DNL1L, confirming that the $\mathrm{Xq} 28$ is an unstable region of the human genome prone to chromosomal rearrangements as demonstrated by diseases such as incontinentia pigmenti, caused by 878 bp MER67B repeats-mediated deletion of the NEMO gene [Aradhya et al., 2001], or hemophilia-A caused by a $\sim 500 \mathrm{~kb}$ inversion disrupting the FVIII gene via an int $22 \mathrm{~h}$ repeat-mediated homologous recombination [Lakich et al., 1993; Naylor et al., 1993]. In addition, the fragile site FRAXE (FMR2) is located on chromosome Xq28, approximately $600 \mathrm{~kb}$ distal to another fragile site FRAXA (FMR1) on $\mathrm{Xq} 27.3$, which is responsible for fragile $\mathrm{X}$ syndrome [Chastain et al., 2006].

Therefore, the Alu-mediated deletion involving both TAZ and DNL1L present in our patient provides further evidence for the instability of the Xq28 region of the X chromosome and broadens the range of genomic alterations observed in Barth syndrome, thus increasing the complexity of the genetic testing for Barth patients.

\section{REFERENCES}

Aradhya S, Woffendin H, Jakins T, Bardaro T, Esposito T, Smahi A, Shaw C, Levy M, Munnich A, D’Urso M, Lewis RA, Kenwrick S, Nelson DL. 2001. A recurrent deletion in the ubiquitously expressed NEMO (IKK-gamma) gene accounts for the vast majority of incontinentia pigmenti mutations. Hum Mol Genet 10:2171-2179.

Barth PG, Scholte HR, Berden JA, Van der Klei-Van Moorsel JM, LuytHouwen IE, Van 't Veer-Korthof ET, Van der Harten JJ, Sobotka-Plojhar MA. 1983. An X-linked mitochondrial disease affecting cardiac muscle, skeletal muscle and neutrophil leucocytes. J Neurol Sci 62: 327-355.

Barth PG, Valianpour F, Bowen VM, Lam J, Duran M, Vaz FM, Wanders RJ. 2004. X-linked cardioskeletal myopathy and neutropenia (Barth syndrome): An update. Am J Med Genet Part A 126A:349-354.

Batzer MA, Deininger PL. 2002. Alu repeats and human genomic diversity. Nat Rev Genet 3:370-379.

Bione S, D'Adamo P, Maestrini E, Gedeon AK, Bolhuis PA, Toniolo D. 1996. A novel X-linked gene, G4.5. is responsible for Barth syndrome. Nat Genet 12:385-389.

Brady AN, Shehata BM, Fernhoff PM. 2006. X-linked fetal cardiomyopathy caused by a novel mutation in the TAZ gene. Prenat Diagn 26:462465.

Chastain PD II, Cohen SM, Brylawski BP, Cordeiro-Stone M, Kaufman DG. 2006. A late origin of DNA replication in the trinucleotide repeat region of the human FMR2 gene. Cell Cycle 5:869-872.

Gedeon AK, Wilson MJ, Colley AC, Sillence DO, Mulley JC. 1995. X linked fatal infantile cardiomyopathy maps to Xq28 and is possibly allelic to Barth syndrome. J Med Genet 32:383-388.

Johnston J, Kelley RI, Feigenbaum A, Cox GF, Iyer GS, Funanage VL, Proujansky R. 1997. Mutation characterization and genotypephenotype correlation in Barth syndrome. Am J Hum Genet 61: 1053-1058.

Kelley RI, Cheatham JP, Clark BJ, Nigro MA, Powell BR, Sherwood GW, Sladky JT, Swisher WP. 1991. X-linked dilated cardiomyopathy with neutropenia, growth retardation, and 3-methylglutaconic aciduria. J Pediatr 119:738-747. 
Lakich D, Kazazian HH Jr, Antonarakis SE, Gitschier J. 1993. Inversions disrupting the factor VIII gene are a common cause of severe haemophilia A. Nat Genet 5:236-241.

Lichtenbelt KD, Sinke RJ, Ausems MG, Kroos MA, Reuser AJ, Wokke JJ. 2006. Frequency of the deletion polymorphism of DNASE1L1 in 137 patients with acid maltase Deficiency (Pompe disease). Exp Mol Pathol 80:308-309.

Malferrari G, Mirabella M, D’Alessandra Y, Servidei S, Biunno I. 2001. Deletion polymorphism of DNASE1L1, an X-linked DNase I-like gene, in acid maltase deficiency disorders. Exp Mol Pathol 70:173174.
Naylor J, Brinke A, Hassock S, Green PM, Giannelli F. 1993. Characteristic mRNA abnormality found in half the patients with severe haemophilia A is due to large DNA inversions. Hum Mol Genet 2: 1773-1778.

Shiokawa D, Matsushita T, Shika Y, Shimizu M, Maeda M, Tanuma S. 2007. DNase $\mathrm{X}$ is a glycosylphosphatidylinositol-anchored membrane enzyme that provides a barrier to endocytosis-mediated transfer of a foreign gene. J Biol Chem 282:17132-17140.

Spencer CT, Bryant RM, Day J, Gonzalez IL, Colan SD, Thompson WR, Berthy J, Redfearn SP, Byrne BJ. 2006. Cardiac and clinical phenotype in Barth syndrome. Pediatrics 118:e337-e346. 